\title{
Correlation Between Hypertension and BMI in Children Over Five Years of Age
}

\author{
Parsa Yousefichaijan ${ }^{1}$, Mina Karimi ${ }^{2}$, Gholamali Fatahibayat ${ }^{1}$, Yazdan Ghandi ${ }^{1}$ and Ali Khosrobeigi ${ }^{2,}{ }^{*}$ \\ ${ }^{1}$ Clinical Research Development Center, Amirkabir Hospital, Arak University of Medical Sciences, Arak, Iran \\ ${ }^{2}$ Students Research Committee, Arak University of Medical Sciences, Arak, Iran \\ "Corresponding author: Students Research Committee, Arak University of Medical Sciences, Arak, Iran. Email: ali.khosrobeigi@yahoo.com \\ Received 2019 March 30; Accepted 2019 May 10.
}

\begin{abstract}
Background: The prevalence of hypertension and obesity is on the rise in children. Both hypertension and obesity are of the most important factors in the development of cardiovascular diseases.

Objectives: Given the importance of hypertension and obesity in children, this study was conducted to determine the incidence of hypertension and obesity in children and investigate the relationship between these two variables.

Methods: This cross-sectional study was conducted on 994 children over five years of age admitted to the Children's Clinic of Amirkabir Hospital in Arak, Iran. Blood pressure was determined by observing the standard blood pressure measurements based on children's gender, age, and height. The BMI of children was determined based on available charts.

Results: Of the 994 children entering the study, $51.1 \%$ were male and $48.9 \%$ were female. The mean age was $7.49 \pm 2.38$ years. The prevalence of obesity was $10.5 \%$ and the prevalence of hypertension was $7 \%$. Based on BMI, the prevalence of hypertension was $19.2 \%$ in obese children and $4.1 \%$ in normal-weight children $(\mathrm{P}<0.001)$.

Conclusions: The condition of hypertension in children is significantly correlated with their obesity.
\end{abstract}

Keywords: Blood Pressure, BMI, Children

\section{Background}

Hypertension (HTN) is becoming a common medical problem in general and pediatric populations. Recent studies showed that the prevalence of HTN is on the rise in children $(1,2)$.

Some studies estimated that the prevalence of HTN is $2 \%-5 \%$ in the pediatric population and it is a common chronic disease in children. Hypertension in children may be essential or secondary to another disease (such as renal disease or endocrine disease). However, secondary hypertension is more common in children $(3,4)$.

HTN is an important risk factor for the incidence of cardiovascular disease as an important cause of morbidity and mortality. Recent studies show that the increased prevalence of hypertension in children is associated with increased cardiovascular risks among adolescents and adults. Pediatric hypertension can cause progressive organ damage and severe complications including heart, brain, kidney, and eye damage (5-7).

Nowadays, along with the increased cardiovascular disease, overweight and obesity have become epidemic, representing major public health problems worldwide (8, 9).

\section{Objectives}

Given the importance of hypertension and obesity in children, we measured the incidence of hypertension and obesity in children and studied the relationship between these two variables.

\section{Methods}

This cross-sectional study was conducted on 994 children at Amirkabir Hospital, Arak, Iran. The children were enrolled in the study based on the inclusion and exclusion criteria. The data on birth weight and the type of neonatal feeding were also recorded. Height, weight, and blood pressure were measured for all children. Blood pressure was measured based on standard methods using the Citizen digital blood pressure monitor (REFCH-311B) (10). If blood pressure was higher than normal, it was measured again after 48 - 72 hours and then recorded. It should also 
be noted that children with hypertension were referred to pediatric nephrologists.

Blood pressure of less than the 90th percentile based on age, gender, and height was considered normal, between the 90th and 95th percentile indicated pre-HTN status, between the 95th and 99th percentile showed HTN grade I, and greater than the 99th percentile plus $5 \mathrm{mmHg}$ denoted HTN grade II (10).

The inclusion criteria included all children over five years of age with no kidney problems and other chronic illnesses. The exclusion criteria were patients who did not cooperate in measuring blood pressure and children who had secondary hypertension.

The study was approved by the Ethics Committee of Arak University of Medical Sciences with ethics code IR.ARAKMU.REC.1396.108. Written informed consent was obtained from the parents of all children.

The data collected through checklists were analyzed by SPSS version 22 software using descriptive statistics for basic information and the chi-square test for qualitative variables. The quantitative variables were analyzed using the independent sample $t$-test, chi-square test, and Fisher exact test. The values of $\mathrm{P}<0.05$ were considered significant.

\section{Results}

The overall mean age of the sample was $7.49 \pm 2.38$ years consisting of $51.1 \%$ boys and $48.9 \%$ girls. The details are summarized in Table 1.

The prevalence rates of systolic HTN and diastolic HTN (including HTN grade I and II) were 3\% and 5.8\% in the

\begin{tabular}{lc}
\hline Table 1. General Characteristics of Children & \\
\hline Parameter & No. $(\%)$ or Mean \pm SD \\
\hline Gender & $508(51.1)$ \\
\hline \multicolumn{1}{c}{ Male } & $486(48.9)$ \\
\hline \multicolumn{1}{c}{ Female } & \\
\hline Gestational age & $34(3.4)$ \\
\hline Pre-term & $958(96.4)$ \\
\hline Term & $2(0.2)$ \\
\hline Post-term & $3.275 \pm 0.507$ \\
\hline Birth weight, kg & \\
\hline Feeding & $923(92.9)$ \\
\hline Breast milk & $71(7.1)$ \\
\hline Formula milk & $7.49 \pm 2.38$ \\
\hline Age, $\mathbf{y}$ & $26.05 \pm 11.14$ \\
\hline Weight, kg & $122.26 \pm 16.19$ \\
\hline
\end{tabular}

general pediatric population, respectively. Moreover, the prevalence of overweight and obesity in the children was $13.2 \%$ and $10.5 \%$, respectively (Table 2 ).

\begin{tabular}{|c|c|}
\hline Parameter & No. (\%) \\
\hline \multicolumn{2}{|l|}{ SBP } \\
\hline Normal & $936(94.2)$ \\
\hline Pre-HTN & $28(2.8)$ \\
\hline HTN grade I & $22(2.2)$ \\
\hline HTN grade II & $8(0.8)$ \\
\hline \multicolumn{2}{|l|}{ DBP } \\
\hline Normal & $895(90)$ \\
\hline Pre-HTN & $41(4.1)$ \\
\hline HTN grade I & $38(3.8)$ \\
\hline HTN grade II & $20(2)$ \\
\hline \multicolumn{2}{|l|}{ BP } \\
\hline Normal & $879(88.4)$ \\
\hline Pre-HTN & $45(4.5)$ \\
\hline HTN & $70(7)$ \\
\hline \multicolumn{2}{|l|}{ BMI } \\
\hline Underweight & $122(12.3)$ \\
\hline Normal & $637(64.1)$ \\
\hline Overweight & $131(13.2)$ \\
\hline Obese & $104(10.5)$ \\
\hline
\end{tabular}

Furthermore, the study showed that the prevalence of HTN had a correlation with birth weight. The prevalence of HTN was higher in children fed with formula milk than in children fed with breast milk. The prevalence of hypertension was $19.2 \%$ in obese children and $4.1 \%$ in normal-weight children $(\mathrm{P}<0.001)$ (Table 3$)$.

\section{Discussion}

Both HTN and obesity in childhood have relationships with HTN and obesity in adulthood. Furthermore, some studies have shown that HTN and obesity in childhood have a relationship with cardiovascular disease in adulthood. Therefore, understanding the relationship between blood pressure status and BMI status is very important to reduce the risk factors of cardiovascular disease $(11,12)$.

The recent study aimed to investigate the association between blood pressure and BMI among children over 5 years of age. The results of this study showed that blood pressure had a significant correlation with BMI. 


\begin{tabular}{|c|c|c|c|c|}
\hline \multirow{2}{*}{ Parameter } & \multicolumn{3}{|c|}{ BP Status } & \multirow{2}{*}{ P Value } \\
\hline & Normal & Pre-HTN & HTN & \\
\hline Feeding, No. (\%) & & & & $<0.001$ \\
\hline Breast milk & $841(91.1)$ & $28(3)$ & $54(5.9)$ & \\
\hline Formula milk & $38(53.5)$ & $17(23.9)$ & $16(22.5)$ & \\
\hline Birth weight, mean \pm SD & $3241 \pm 484$ & $3514 \pm 679$ & $3555 \pm 537$ & $<0.001$ \\
\hline BMI, No. (\%) & & & & $<0.001$ \\
\hline Underweight & $114(93.4)$ & $0(0)$ & $8(6.6)$ & \\
\hline Normal & $591(92.8)$ & $20(3.1)$ & $26(4.1)$ & \\
\hline Overweight & $102(77.9)$ & $13(9.9)$ & $16(12.2)$ & \\
\hline
\end{tabular}

Similar to our study, Basiratnia et al. reported that there was a significant relationship between BMI and hypertension in children and that both SBP and DBP significantly increased with obesity (13). He et al. found that the prevalence of HTN was $19.4 \%$ in obese children and $7 \%$ in non-obese children (14). Similar to our results, Falkner et al. found that SBP and DBP increased in children with increasing BMI (15).

Another study conducted by Madruga et al. showed a direct relationship between the waist-to-height ratio and the incidence of hypertension in adolescents (8). Kuwabara et al. in a five-year cohort study reported that obesity increased the risk of HTN (16).

This study had some limitations. Some of the parents did not cooperate in the study and did not return for blood pressure measurement of their children. Therefore, these children were excluded from the study.

\subsection{Conclusions}

According to the results of the current study, it seems that the prevalence of hypertension was higher in the obese population than in the normal-weight population of children over five years of age. Therefore, overweight and obese children should be more closely monitored for their blood pressure and should begin weight loss treatment as soon as possible. Furthermore, this study showed that the prevalence of HTN was more in children fed with formula milk than in children fed with breast milk.

However, these findings require more evidence from further investigations. Similar studies at different centers are proposed to help these patients. Moreover, similar studies are needed to investigate the effect of formula milk on blood pressure.

\section{Acknowledgments}

The authors gratefully acknowledge the Research Committee of Arak University of Medical Sciences (grant number: 2722) for financial support. This work was performed in partial fulfillment of the requirements for the degree of Medical Doctor by Mina Karimi at the School of Medicine, Arak University of Medical Sciences, Arak, Iran.

\section{Footnotes}

Authors' Contribution: Study concept and design: Parsa Yousefichaijan, Gholamali Fatahibayat, and Yazdan Ghandi; acquisition of data: Mina Karimi; analysis and interpretation of data: Ali Khosrobeigi; drafting of the manuscript: Ali Khosrobeigi; critical revision of the manuscript for important intellectual content: Parsa Yousefichijan; statistical analysis: Ali Khosrobeigi; study supervision: Parsa Yousefichaijan.

\section{Conflict of Interests: None.}

Ethical Approval: The study was approved by the Ethics Committee of Arak University of Medical Sciences with ethics code IR.ARAKMU.REC.1396.108.

Funding/Support: The Research Committee of Arak University of Medical Sciences (grant number: 2722) financially supported this study.

Patient Consent: Written informed consent was obtained from the parents of all children.

\section{References}

1. Cha SD, Chisolm DJ, Mahan JD. Essential pediatric hypertension: Defining the educational needs of primary care pediatricians. BMC Med Educ. 2014;14:154. doi: 10.1186/1472-6920-14-154. [PubMed: 25063988]. [PubMed Central: PMC4124498]. 
2. Gomes RS, Quirino IG, Pereira RM, Vitor BM, Leite AF, Oliveira EA, et al. Primary versus secondary hypertension in children followed up at an outpatient tertiary unit. Pediatr Nephrol. 2011;26(3):441-7. doi: 10.1007/s00467-010-1712-x. [PubMed: 21174218].

3. Hansen ML, Gunn PW, Kaelber DC. Underdiagnosis of hypertension in children and adolescents. JAMA. 2007;298(8):874-9. doi: 10.1001/jama.298.8.874. [PubMed: 17712071].

4. Yousefichaijan P, Khosrobeigi A, Soltani M, Ghandi Y, Mojtahedi F. Evaluation of blood pressure in children with idiopathic overactive bladder syndrome. Saudi J Kidney Dis Transpl. 2018;29(3):540-4. doi: 10.4103/1319-2442.235177. [PubMed: 29970729].

5. Alkahtani SA. Pediatric hypertension in the eastern province of Saudi Arabia. Saudi Med J. 2015;36(6):713-9. doi: 10.15537/smj.2015.6.10479. [PubMed: 25987114]. [PubMed Central: PMC4454906].

6. Mirmoeini Y, Yousefichaijan P, Kahbazi M, Parsa P, Khosrobeigi A. Correlation between asymptomatic persistent microscopic hematuria and reflux nephropathy. Nephro Urol Mon. 2019;In Press(In Press). doi: 10.5812/numonthly.86920.

7. Bassareo PP, Mercuro G. Pediatric hypertension: An update on a burning problem. World J Cardiol. 2014;6(5):253-9. doi: 10.4330/wjc.v6.i5.253. [PubMed: 24944755]. [PubMed Central: PMC4062118].

8. Madruga JG, Moraes Silva F, Scherer Adami F. Positive association between waist-to-height ratio and hypertension in adolescents. Revista Portuguesa de Cardiologia (English Edition).2016;35(9):479-84. doi: 10.1016/j.repce.2016.03.006

9. Yoshinaga M, Hatake S, Tachikawa T, Shinomiya M, Miyazaki A, Takahashi H. Impact of lifestyles of adolescents and their parents on cardiovascular risk factors in adolescents. J Atheroscler Thromb. 2011;18(11):981-90. doi: 10.5551/jat.9514. [PubMed: 21836372].
10. Yousefichaijan P, Ghandi Y, Alavi M, Rafiei M, Khosrobeigi A, Arjmand A, et al. Evaluation of blood pressure in children with hydronephrosis in comparison with healthy children. Nephro Urol Mon. 2018;10(4) doi: 10.5812/numonthly.68998.

11. Parker ED, Sinaiko AR, Kharbanda EO, Margolis KL, Daley MF, Trower $\mathrm{NK}$, et al. Change in weight status and development of hypertension. Pediatrics. 2016;137(3). e20151662. doi: 10.1542/peds.2015-1662. [PubMed: 26908707]. [PubMed Central: PMC4771125].

12. Juhola J, Magnussen CG, Viikari JS, Kahonen M, Hutri-Kahonen N, Jula A, et al. Tracking of serum lipid levels, blood pressure, and body mass index from childhood to adulthood: The Cardiovascular Risk in Young Finns Study. J Pediatr. 2011;159(4):584-90. doi 10.1016/j.jpeds.2011.03.021. [PubMed: 21514597].

13. Basiratnia M, Derakhshan D, Ajdari S, Saki F. Prevalence of child hood obesity and hypertension in south of Iran. Iran J Kidney Dis. 2013;7(4):282-9. [PubMed: 23880805].

14. He Q, Ding ZY, Fong DY, Karlberg J. Blood pressure is associated with body mass index in both normal and obese children. Hypertension. 2000;36(2):165-70. doi: 10.1161/01.HYP.36.2.165. [PubMed: 10948072]

15. Falkner B, Gidding SS, Ramirez-Garnica G, Wiltrout SA, West D, Rappaport EB. The relationship of body mass index and blood pressure in primary care pediatric patients.J Pediatr. 2006;148(2):195-200. doi 10.1016/j.jpeds.2005.10.030. [PubMed: 16492428].

16. Kuwabara M, Kuwabara R, Hisatome I, Niwa K, Roncal-Jimenez CA, Bjornstad P, et al. "Metabolically healthy" obesity and hyperuricemia increase risk for hypertension and diabetes: 5-year Japanese cohort study. Obesity (Silver Spring). 2017;25(11):1997-2008. doi: 10.1002/oby.22000. [PubMed: 28922565]. [PubMed Central: PMC5846469]. 